\title{
Distribution and Genetic Diversity of Aedes aegypti Subspecies across the Sahelian Belt in Sudan
}

\author{
Sara Abdelrahman Abuelmaali 1,2, Jamsari Amirul Firdaus Jamaluddin ${ }^{1} \mathbb{D}$, Kheder Noaman ${ }^{3} \mathbb{D}$, Mushal Allam $^{4} \mathbb{D}^{\mathbb{D}}$, \\ Hind Mohammad Abushama ${ }^{5}$ (D), Dia Eldin Elnaiem ${ }^{6}$, Intan Haslina Ishak ${ }^{1}$, Mustafa Fadzil Farid Wajidi ${ }^{7}$, \\ Zairi Jaal ${ }^{8}$ and Nur Faeza Abu Kassim ${ }^{1, * \mathbb{D}}$
}

Citation: Abuelmaali, S.A.; Jamaluddin, J.A.F.; Noaman, K.; Allam, M.; Abushama, H.M.; Elnaiem, D.E.; Ishak, I.H.; Wajidi, M.F.F.; Jaal, Z.; Abu Kassim, N.F. Distribution and Genetic Diversity of Aedes aegypti Subspecies across the Sahelian Belt in Sudan. Pathogens 2021, 10, 78. https://doi.org/10.3390/pathogens 10010078

Received: 20 November 2020

Accepted: 13 January 2021

Published: 17 January 2021

Publisher's Note: MDPI stays neutral with regard to jurisdictional claims in published maps and institutional affiliations.

Copyright: (c) 2021 by the authors. Licensee MDPI, Basel, Switzerland. This article is an open access article distributed under the terms and conditions of the Creative Commons Attribution (CC BY) license (https:// creativecommons.org/licenses/by/ $4.0 /)$.
1 School of Biological Sciences, Universiti Sains Malaysia, Penang 11800, Malaysia; Sarabuelmaali@Student.usm.my (S.A.A.); jamsari_85@yahoo.com (J.A.F.J.); intanishak@usm.my (I.H.I.)

2 National Public Health Laboratory, Federal Ministry of Health, Khartoum 11115, Sudan

3 National Center for Research, Tropical Medicine Research Institute, Khartoum 1304, Sudan; khedernoaman@gmail.com

4 National Institute for Communicable Diseases, National Health Laboratory Service, Johannesburg 2131, South Africa; mushalallam@gmail.com

5 Department of Zoology, Faculty of Science, University of Khartoum, Khartoum 321, Sudan; hindabushama@hotmail.com

6 Department of Natural Sciences, University of Maryland Eastern Shore, Maryland, MD 21853, USA; dialnaiem@gmail.com

7 Molecular Entomology Research Group, School of Distance Education, Universiti Sains Malaysia, Penang 11800, Malaysia; mfadzil@usm.my

8 Vector Control Research Unit, School of Biological Sciences, Universiti Sains Malaysia, Penang 11800, Malaysia; zairi@usm.my

* Correspondence: nurfaeza@usm.my

\begin{abstract}
Aedes aegypti is the most important arboviral disease vector worldwide. In Africa, it exists as two morphologically distinct forms, often referred to as subspecies, Aaa and Aaf. There is a dearth of information on the distribution and genetic diversity of these two forms in Sudan and other African Sahelian region countries. This study aimed to explore the distribution and genetic diversity of Aedes aegypti subspecies using morphology and Cytochrome oxidase- 1 mitochondrial marker in a large Sahelian zone in Sudan. An extensive cross-sectional survey of Aedes aegypti in Sudan was performed. Samples collected from eight locations were morphologically identified, subjected to DNA extraction, amplification, sequencing, and analyses. We classified four populations as Aaa and the other four as Aaf. Out of 140 sequence samples, forty-six distinct haplotypes were characterized. The haplotype and nucleotide diversity of the collected samples were 0.377-0.947 and 0.002-0.01, respectively. Isolation by distance was significantly evident $(\mathrm{r}=0.586, p=0.005)$. The SAMOVA test indicated that all Aaf populations are structured in one group, while the Aaa clustered into two groups. AMOVA showed 53.53\% genetic differences within populations and $39.22 \%$ among groups. Phylogenetic relationships indicated two clusters in which the two subspecies were structured. Thus, the haplotype network consisted of three clusters.
\end{abstract}

Keywords: mitochondrial DNA; cytochrome oxidase-1 (CO1); Aedes aegypti aegypti; Aedes aegypti formosus; haplotype; Sudan

\section{Introduction}

Aedes aegypti (Ae. aegypti), which is commonly known as the yellow fever mosquito, is recognized for the transmission of the most significant arboviral diseases, including dengue, chikungunya, and zika viruses [1,2] It is estimated that $70 \%$ (831 million) of the African population is vulnerable to arboviral disease infections [3].

This species is a tropical and subtropical mosquito with distribution throughout the globe but native to Sub-Saharan and African Sahelian regions, including Senegal, 
Cameroon, Kenya, Nigeria, Morocco, Western Sahara, Algeria, Tunisia, Egypt, and Sudan $[4,5]$. Known as the domestic mosquito, Ae. aegypti feeds on humans (anthropophilic) during the daytime hours. It also rests at indoor sites and breeds within and around the human environment, particularly in man-made containers (e.g., water jars, barrels, and tires) $[6,7]$.

Unlike other continents, two forms or subspecies are known in Africa; Ae. aegypti aegypti (Aaa) and Ae. aegypti formosus (Aaf). Ae. aegypti aegypti is a light pale brown color form with white abdominal scales. It is known as the domestic subspecies, with strict breeding in human-made artificial containers and marked anthropophagy. On the other hand, Ae. aegypti formosus is darker in color and lacks the white abdominal scales. This form/subspecies is more sylvatic, breeding in natural habitats, such as tree holes, and more zoophilic [8,9]. The dark form (Aaf) is confined entirely to Africa, the south of the Sahara, its northern borders in Sudan, as shown by Lewis [10]. It has been reported from many parts of Africa, including Liberia, Kenya, Senegal, Ghana, Uganda, and Sudan. It has been also suggested that the dark form is perhaps abundant all over Africa [11-15].

The Ae. aegypti subspecies are known to vary in their disease transmission capacity, Aaa populations have a considerably higher vector competence for both dengue virus (DENV-2) and YF virus than Aaf $[16,17]$. Since the two subspecies show different susceptibilities to dengue viruses, it is important to understand their distribution and role in disease transmission. Therefore, a number of genetic markers have been developed to understand genetic variations in Aedes aegypti vectors and the genetic structure of its populations, and the phylogenetic and genetic diversity of Aedes aegypti have been characterized in different parts of the world since 1971 [18]. These markers include both biochemical and molecular tools, such as allozymes, nuclear DNA, microsatellites, and mitochondrial DNA [14,19-23]. Due to their maternal inheritance and rapid divergence, the mitochondrial DNA markers have been used extensively in phylogenetic, evolutionary, and population genetics studies of Aedes aegypti worldwide [24]. However, little has been done on the genetic structuring of the two subspecies in the African Sahelian region.

In Sudan, Ae. aegypti was described for the first time in Khartoum by Balfour (1903) [25]. In a subsequent study, the vector was reported widely in various geographical localities in Sudan including the eastern regions (Port Sudan and Kassala), central Sudan (Wad Medani and Khartoum), western regions (Al Fasher, and Al Junaynah), and the Nuba mountains in the south $[8,25,26]$. More recently, several studies documented the presence of Aedes aegypti in endemic foci of dengue, chikungunya, and yellow fever. The absence of other possible vectors in these locations suggests the definitive role of Ae. aegypti in the transmission of the viruses causing these diseases [27-29]. However, no data were published on infections of the viruses in the vector in the area.

Since the 18th century and for decades, Sudan has suffered from many arboviral diseases [30]. In 1955, Lewis emphasized the role of Aedes aegypti in yellow fever and dengue outbreaks in the country [10]. This notion was supported by several subsequent reports since the species was found in all areas where arbovirus outbreaks have occurred [27,30-33]. Dengue fever viruses have existed for decades, particularly in the eastern parts of the country [30,31,34]; however, recently, in 2015, the first dengue outbreak in the western part (Darfur) of the country occurred, with considerable other outbreaks having been mentioned in the country since 1908, and epidemics have continued to occur many times, causing extensive mortality [27]. Chikungunya viruses have also been reported in Sudan many times from different geographical areas [35-38] and a recent fatal chikungunya outbreak was reported in 2018-2019 in various regions in Sudan [30,39]. Yellow fever (YF) outbreaks have been reported in Sudan since 1940 and continue to occur, with severe outbreaks in recent decades $[30,33]$.

Despite the crucial involvement of Ae. aegypti as a vector of yellow fever, dengue fever, chikungunya, and other arboviral diseases in Sudan, little is known about its distribution, population dynamics, genetic structure, and genetic variations across different endemic ge- 
ographical areas of the country. Proper knowledge of these aspects should help to provide a better understanding of the epidemiology of arboviral diseases and their control [40].

This study was designed to investigate the distribution and genetic diversity of the two subspecies of Aedes aegypti across the Sahelian belt in Sudan. Using the cytochrome oxidase marker, we compared the genetic diversity within and between the two subspecies in different areas of Sudan.

\section{Results}

\subsection{Morphological and Molecular Identification of Ae. aegypti at Eight Sites of Sudan}

We found Ae. aegypti in all eight study sites in Sudan. All samples were identified by morphological features, without ambiguities. Additionally, the species identification was positively confirmed by amplification and Rsal restriction enzyme analysis of the ITS1 region (700 bp) from ten Aedes mosquito samples.

The morphological identification of mosquitoes collected in this study showed that both subspecies of Ae. aegypti are present in Sudan. The 100 adult females that emerged from samples taken from each site of four towns located in the eastern and central part of the county, namely Port Sudan (P), Tokar (T), Kassala (K), and Barakat/Gezira (G), were morphologically identified as the domestic form/subspecies Aaa, while the Aedes mosquitoes from the western and southern parts (Darfur and Kordofan) were identified as the wild form/subspecies Aaf: Nyala (N), Al Fasher (F), Al Junaynah (J) and Kadugli (D) (Table 1). The distribution of the two subspecies was differentiated between the western and the eastern parts of Sudan, with the White Nile and the main Nile separating the locations of their respective samples (Figure 1).

Table 1. Samples collection sites, their numbers, and the subspecies distribution, site coordinates, and larval habitats.

\begin{tabular}{|c|c|c|c|c|c|c|c|}
\hline Code & Site & Region & Subspecies & Coordinates & Collection Year & Larval Habitats & NO \\
\hline $\mathbf{P}$ & Port Sudan & Coastal/Eastern & $A a a$ & $\begin{array}{l}19.617^{\circ} 37^{\prime} 0^{\prime \prime} \mathrm{N} \\
37.217^{\circ} 13^{\prime} 0^{\prime \prime} \mathrm{E}\end{array}$ & 2014 & $\begin{array}{l}\text { Clay pots, cement } \\
\text { water reservoir, } \\
\text { plastic barrels and } \\
\text { jerrycans }\end{array}$ & 26 \\
\hline $\mathbf{T}$ & Tokar & Eastern & $A a a$ & $\begin{array}{l}18.425^{\circ} 25^{\prime} 31^{\prime \prime} \mathrm{N} \\
37.729^{\circ} 43^{\prime} 45^{\prime \prime} \mathrm{E}\end{array}$ & 2016 & $\begin{array}{l}\text { Clay pots and } \\
\text { jerrycans. }\end{array}$ & 22 \\
\hline $\mathbf{K}$ & Kassala & Eastern & $A a a$ & $\begin{array}{l}15.45^{\circ} 27^{\prime} 0^{\prime \prime} \mathrm{N} \\
36.4^{\circ} 24^{\prime} 0^{\prime \prime} \mathrm{E}\end{array}$ & 2014 & $\begin{array}{l}\text { Flowerpots, } \\
\text { cement reservoir, } \\
\text { and clay pots. }\end{array}$ & 13 \\
\hline G & Barakat/Gezira & Central & $A a a$ & $\begin{array}{c}14.314^{\circ} 18^{\prime} 50.84^{\prime \prime} \\
\mathrm{N}, 33.534^{\circ} 32^{\prime} \\
3.74^{\prime \prime} \mathrm{E}\end{array}$ & 2014 & $\begin{array}{l}\text { Plastic barrels, } \\
\text { tyres, and bathtubs }\end{array}$ & 20 \\
\hline D & Kadugli & South & Aaf & $\begin{array}{l}11.017^{\circ} 1^{\prime} 0^{\prime \prime} \mathrm{N}, \\
29.717^{\circ} 43^{\prime} 0^{\prime \prime} \mathrm{E}\end{array}$ & 2015 & $\begin{array}{l}\text { Tyres, clay pots, } \\
\text { and plastic barrels }\end{array}$ & 30 \\
\hline $\mathbf{N}$ & Nyala & West & Aaf & $\begin{array}{l}12.036^{\circ} 2^{\prime} 11^{\prime \prime} \mathrm{N}, \\
24.878^{\circ} 52^{\prime} 37^{\prime \prime} \mathrm{E}\end{array}$ & 2016-2017 & $\begin{array}{l}\text { Clay pots and } \\
\text { jerrycans }\end{array}$ & 16 \\
\hline $\mathbf{F}$ & Al Fasher & Northern West & Aaf & $\begin{array}{c}13.631^{\circ} 37^{\prime} 50^{\prime \prime} \mathrm{N}, \\
25.35^{\circ} 21^{\prime} 0^{\prime \prime} \mathrm{E}\end{array}$ & 2017 & $\begin{array}{l}\text { Clay pots and } \\
\text { jerrycans }\end{array}$ & 22 \\
\hline $\mathbf{J}$ & Al Junaynah & West & Aaf & $\begin{array}{l}13.45^{\circ} 27^{\prime} 0^{\prime \prime} \mathrm{N} \\
22.45^{\circ} 27^{\prime} 0^{\prime \prime} \mathrm{E}\end{array}$ & 2014 & $\begin{array}{l}\text { Clay pots, cement } \\
\text { barrels, and plastic } \\
\text { containers }\end{array}$ & 8 \\
\hline
\end{tabular}

NO: number of mosquitoes used in population diversity study, Aaa: Aedes aegypti aegypti, Aaf: Aedes aegypti formosus.

The aquatic stages of Aedes aegypti were collected from different larval habitats inside homes or around human dwellings. The most dominant larval habitats that yielded most of the larvae for both Ae. aegypti subspecies were clay-pots, "Zeirr", used for drinking 
water, followed by barrels and jerry cans, cement water reservoirs, tires, flower vases, old unused bathtubs, and other water containers (Table 1).

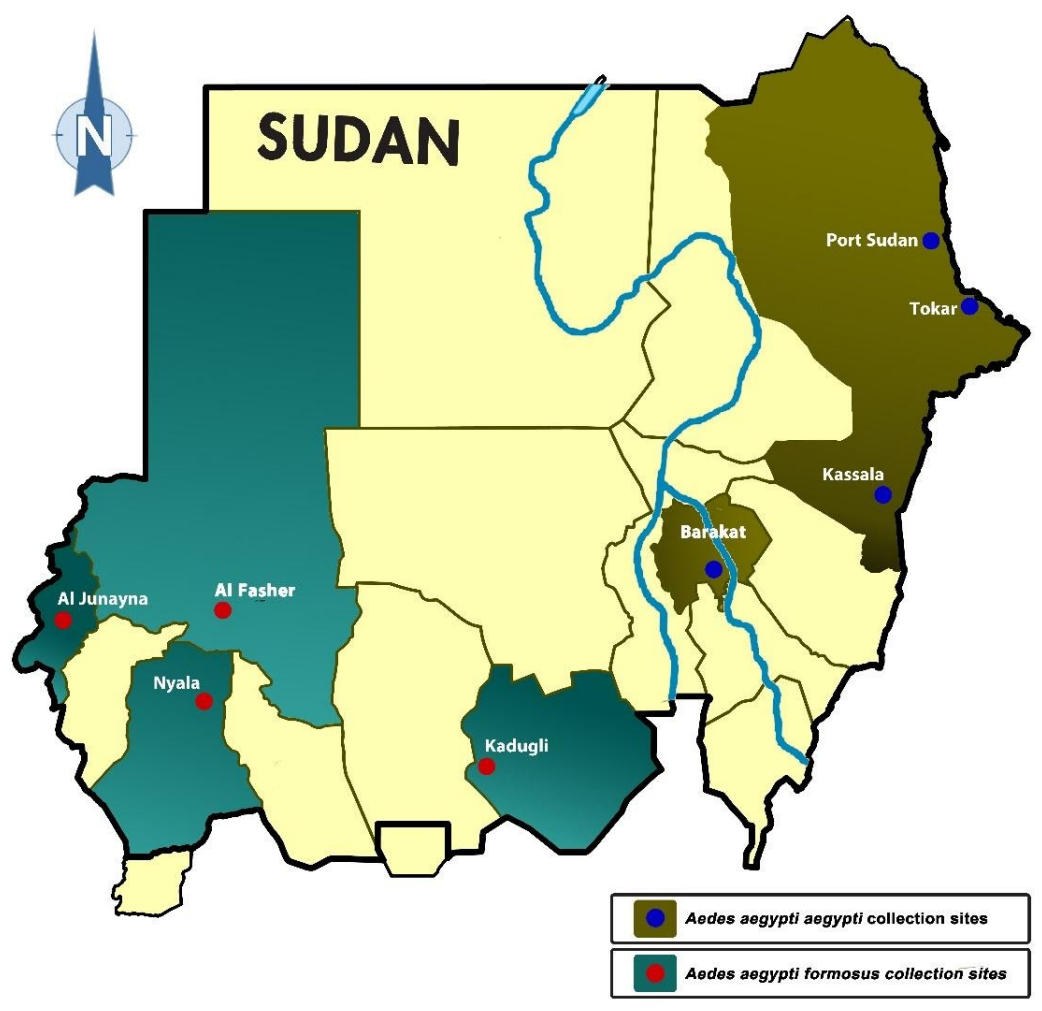

Figure 1. Map of Sudan showing the location of two subspecies/forms of Aedes aegypti collected in 8 sites. Note all Ae. aegypti aegypti were found in the east, whereas Ae. aegypti formosus was found in the west, with the main Nile and the White Nile separating their collection sites.

\subsection{Mitochondrial Haplotype Analysis}

Following the amplification of an $860 \mathrm{bp}$ fragment of the $\mathrm{CO} 1$ gene, the successfully sequenced samples were cleaned and trimmed to generate a final $603 \mathrm{bp}$ fragment of CO1 sequences which was subjected to analyses. Forty-six distinct haplotypes were identified out of 140 female Aedes aegypti mosquitoes collected from all eight sites in Sudan. The numbers and diversity of these haplotypes are described in Table 2, and their relationships are illustrated in the median-joining haplotype network tree shown in Figure 2. Of these samples, nine haplotypes were shared by more than one individual mosquito, while 37 haplotypes were singletons, detected in a single mosquito (Table 2).

Table 2. Molecular diversity indices and neutrality tests of CO1 mitochondrial sequences of Aedes aegypti subspecies/forms from eight study sites in Sudan.

\begin{tabular}{ccccccccc}
\hline Site & Subspecies/Form & $\mathbf{N}$ & $\mathbf{S}$ & $\mathbf{H}$ & Hd & $\boldsymbol{\pi}$ & Tajima's D & Fu's F \\
\hline Port Sudan & Aaa/domestic & 24 & 6 & 5 & 0.377 & 0.002 & -1.319 & -1.142 \\
Tokar & Aaa/domestic & 25 & 14 & 16 & 0.947 & 0.007 & 0.592 & -6.792 \\
Kassala & Aaa/domestic & 13 & 17 & 5 & 0.539 & 0.008 & -0.606 & 2.254 \\
Barakat/Gezira & Aaa/domestic & 14 & 14 & 5 & 0.791 & 0.010 & 1.500 & 3.419 \\
Kadugli & Aaf/wild & 27 & 26 & 14 & 0.920 & 0.009 & -0.892 & -2.899 \\
Nyala & Aaf/wild & 10 & 10 & 8 & 0.933 & 0.004 & -1.507 & -4.469 \\
Al Fasher & Aaf/wild & 21 & 5 & 4 & 0.610 & 0.003 & 1.076 & 1.690 \\
Al Junaynah & Aaf/wild & 5 & 11 & 3 & 0.700 & 0.007 & -1.200 & 2.054 \\
\hline
\end{tabular}

$\mathrm{N}$, sample size; $\mathrm{S}$ number of polymorphic sites; $\mathrm{H}$, number of haplotypes; $\mathrm{Hd}$, haplotype diversity; $\pi$, nucleotide diversity; $\mathrm{S}$, number of segregating sites; D, Tajima's statistics; Fu's F s statistics. 


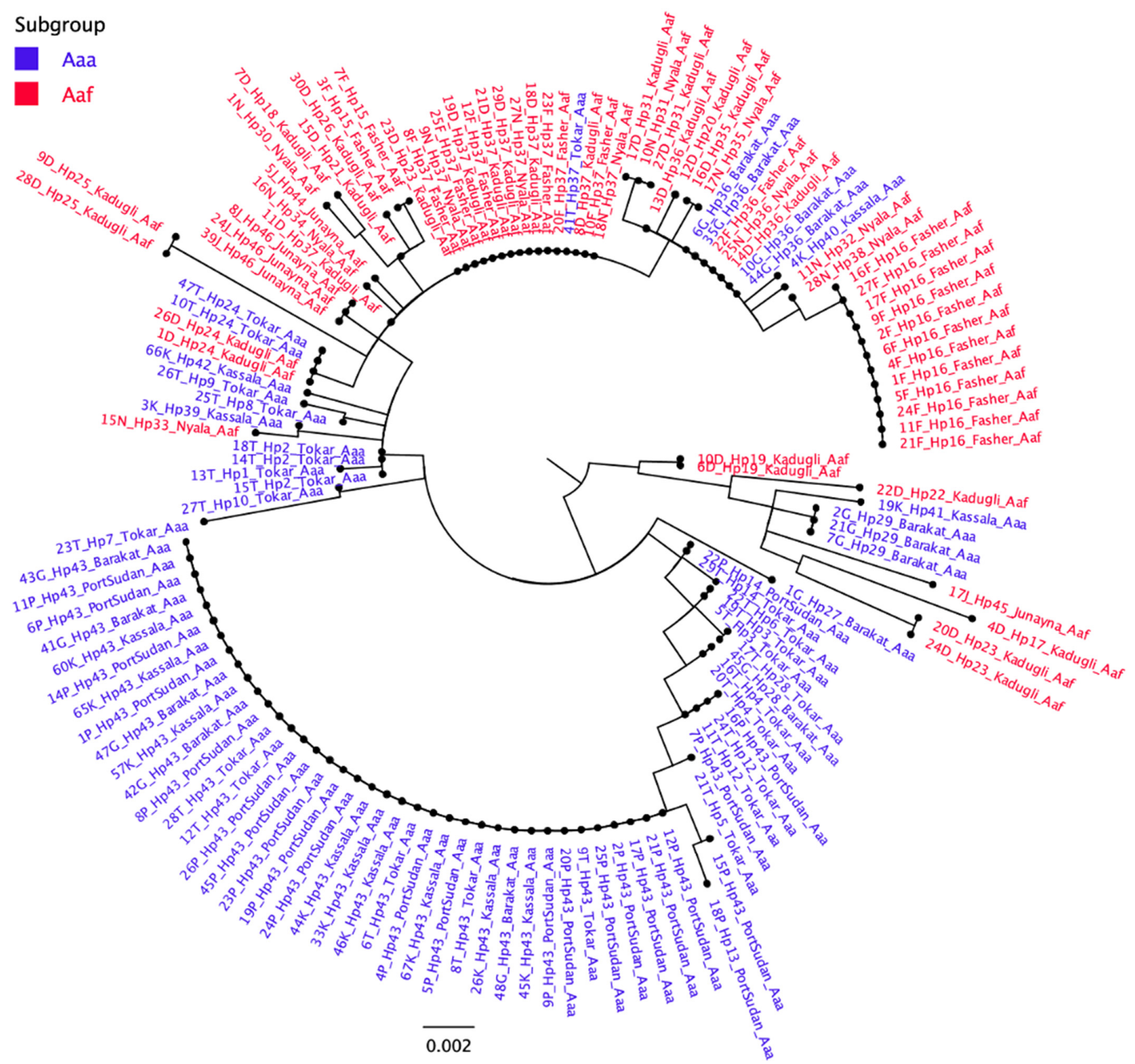

Figure 2. Median-joining haplotype network tree of Ae. aegypti subspecies/populations from 8 sites in Sudan. The tree was constructed using 46 haplotype CO1 mtDNA sequences from the eight study sites of Sudan. The size of each circle indicates the frequency of the incidence of each haplotype in the study populations. Between two haplotypes there is a minimum of one mutation. The network consists of two Groups including haplotypes from both Aaa and Aaf populations.

There was a clear variation in the number of haplotypes in each study site (Table 2). In descending order, the numbers of haplotypes in different sites were 16 in Tokar, 14 in Kadugli, 8 in Nyala, 5 in Barakat, Kassala, and Port Sudan, 4 in Al Fasher, and 3 in Al Junaynah (Table 2). Each site had a number of unique haplotypes not found in other sites. In total, there were 33 site-specific haplotypes. On the other hand, two haplotypes (Hap 43 and 37) appeared to have a higher prevalence in all Aaa and Aaf populations, respectively (Figure 2). Hap 43 was found in $49.35 \%$ of all Aaa subspecies samples and occurred in all eastern Sudan study sites. In comparison, Hap 37 occurred in $27.14 \%$ of Aaf samples (Figure 2) and was found in all western Sudan sites, except Al Junaynah.

Three haplotypes were shared by some Aaa and Aaf populations. Hap 24 was found in two Aaf in Kadugli and two Aaa in Tokar. Hap 36 occurred in four Aaa samples in Barakat and four Aaf samples from Nyala, Al Fashir, and Kadugli. Hap 37 occurred in one Aaa sample in Tokar and 16 Aaf samples from Nyala, Al Fashir, and Kadugli (Figure 2). 
Although the number of polymorphic sites and the nucleotide diversity were similar for the two Ae. aegypti subspecies (Number of polymorphic sites = 51 in Aaa and 52 in Aaf; Table 2), the level of haplotype diversity appeared to be consistently higher in Aaf ( 0.61 in Al Fashir, 0.7 in Al Junaynah, 0.92 in Kadugli and 0.933 in Nyala) than in Aaa (0.377 in Port Sudan, 0.539 in Kassala, 0.791 in Barakat and 0.947 in Tokar). Overall, Port Sudan appeared to have the lowest genetic diversity of Aedes aegypti compared to all other sites (Table 2).

\subsection{Genetic Variance (Pairwise $F_{S T}$ ) and Mantel Test Results}

The overall subpopulation genetic variance (Pairwise $\mathrm{F}_{\mathrm{ST}}$ values) showed values ranging from 0.015 (between Fasher and Kadugli Aaf populations) and 0.848 (between Fasher Aaf and Port Sudan Aaa populations) (Table 3). All between-population F ST $_{\text {values }}$ were significant $(p<0.05)$, except between Kadugli and Barakat, Kadugli and Nyala, Kassala and Junaynah, Barakat and Junaynah, and Kadugli and Junaynah (Table 4).

Table 3. Population divergence between samples ( $\mathrm{F}_{\mathrm{ST}}$ value) was performed in ARLEQUIN version 3.5 among eight populations of Aedes aegypti subspecies from Sudan.

\begin{tabular}{cccccccc}
\hline Site (form) & $\mathbf{P}($ Aaa $)$ & $\mathrm{T}($ Aaa $)$ & $\mathrm{K}($ Aaa $)$ & $\mathrm{G}($ Aaa $)$ & $\mathbf{D}($ Aaf) & $\mathbf{N}($ Aaf) & $\mathbf{F}($ Aaf) \\
\hline P (Aaa) & & & & & & & \\
T (Aaa) & 0.425 & & & & & & \\
K (Aaa) & 0.125 & 0.158 & & & & & \\
G (Aaa) & 0.389 & 0.097 & 0.045 & & & & \\
D (Aaf) & 0.652 & 0.248 & 0.396 & 0.186 & & & \\
F (Aaf) & 0.848 & 0.355 & 0.545 & 0.309 & 0.015 & & \\
N (Aaf) & 0.837 & 0.421 & 0.603 & 0.384 & 0.160 & 0.191 & \\
J (Aaf) & 0.782 & 0.252 & 0.352 & 0.124 & 0.037 & 0.205 & 0.366 \\
\hline
\end{tabular}

Table 4. Probabilities (P values) of the Pairwise divergence $\left(\mathrm{F}_{\mathrm{ST}}\right)$ between eight populations subspecies of Aedes aegypti in Sudan.

\begin{tabular}{ccccccccc}
\hline $\begin{array}{c}\text { Site } \\
\text { (form) }\end{array}$ & $\mathbf{P}($ Aaa) & T (Aaa) & K (Aaa) & $\begin{array}{c}\text { G } \\
\text { (Aaa) }\end{array}$ & D (Aaf) & N (Aaf) & F (Aaf) & $\begin{array}{c}\text { J } \\
\text { (Aaf) }\end{array}$ \\
\hline $\mathbf{P ~ ( A a a ) ~}$ & & & & & & & & \\
\hline T (Aaa) & 0.000 & & & & & & & \\
K (Aaa) & 0.021 & 0.014 & & & & & & \\
G (Aaa) & 0.000 & 0.030 & $\mathbf{0 . 1 7 2}$ & & & & & \\
D (Aaf) & 0.000 & 0.000 & 0.000 & 0.001 & & & & \\
N (Aaf) & 0.000 & 0.000 & 0.000 & 0.002 & $\mathbf{0 . 2 6 7}$ & & \\
F (Aaf) & 0.000 & 0.000 & 0.000 & 0.000 & 0.000 & 0.014 & & \\
J (Aaf) & 0.000 & 0.008 & 0.007 & $\mathbf{0 . 0 8 7}$ & $\mathbf{0 . 1 5 6}$ & 0.004 & 0.000 & \\
\hline
\end{tabular}

Bold numbers indicate the nonsignificant at $p>0.05$.

The Mantel test revealed a medium to strong significant relationship between geographic distance and genetic differentiation correlation coefficient value $(\mathrm{r})=0.586$, $p=0.005$ (Figure 3). However, there were some deviations from this relationship, since some sites showed higher $\mathrm{F}_{\mathrm{ST}}$ values with a nearer site than another site lying farther away. A case in point is the $\mathrm{F}_{\mathrm{ST}}$ for the Aaf populations of Al Fashir and Kadugli (Distance $=553 \mathrm{~km}$, and $\left.\mathrm{F}_{\mathrm{ST}}=0.015\right)$ and Al Fashir and Junaynah towns (distance $=303 \mathrm{~km}$, and $\mathrm{F}_{\mathrm{ST}}=0.366$ ). Another example is the $\mathrm{F}_{\mathrm{ST}}$ for Port Sudan and Tokar Aaa populations (Distance $=141 \mathrm{~km} ; \mathrm{F}_{\mathrm{ST}}=0.425$ ) and in Port Sudan and Barakat populations (Distance $=700 \mathrm{~km}$; $\left.\mathrm{F}_{\mathrm{ST}}=0.389\right)$.

\subsection{Genetic Structure of Aedes aegypti in Different Study Sites}

The polar unrooted maximum-likelihood phylogenetic tree for 140 individuals Aedes aegypti from the eight study sites revealed two big clusters (Figure 4); most of the Aaa haplotypes clustered and appeared to be genetically structured, while the haplotypes of Aaf were represented by one group. It must be pointed out that there were some 
exceptions to this rule, as some samples from Tokar and Barakat/Gezira Aaa shared the same haplotypes with the Aaf populations haplotypes and clustered with them under the same cluster/branch (Figure 3).

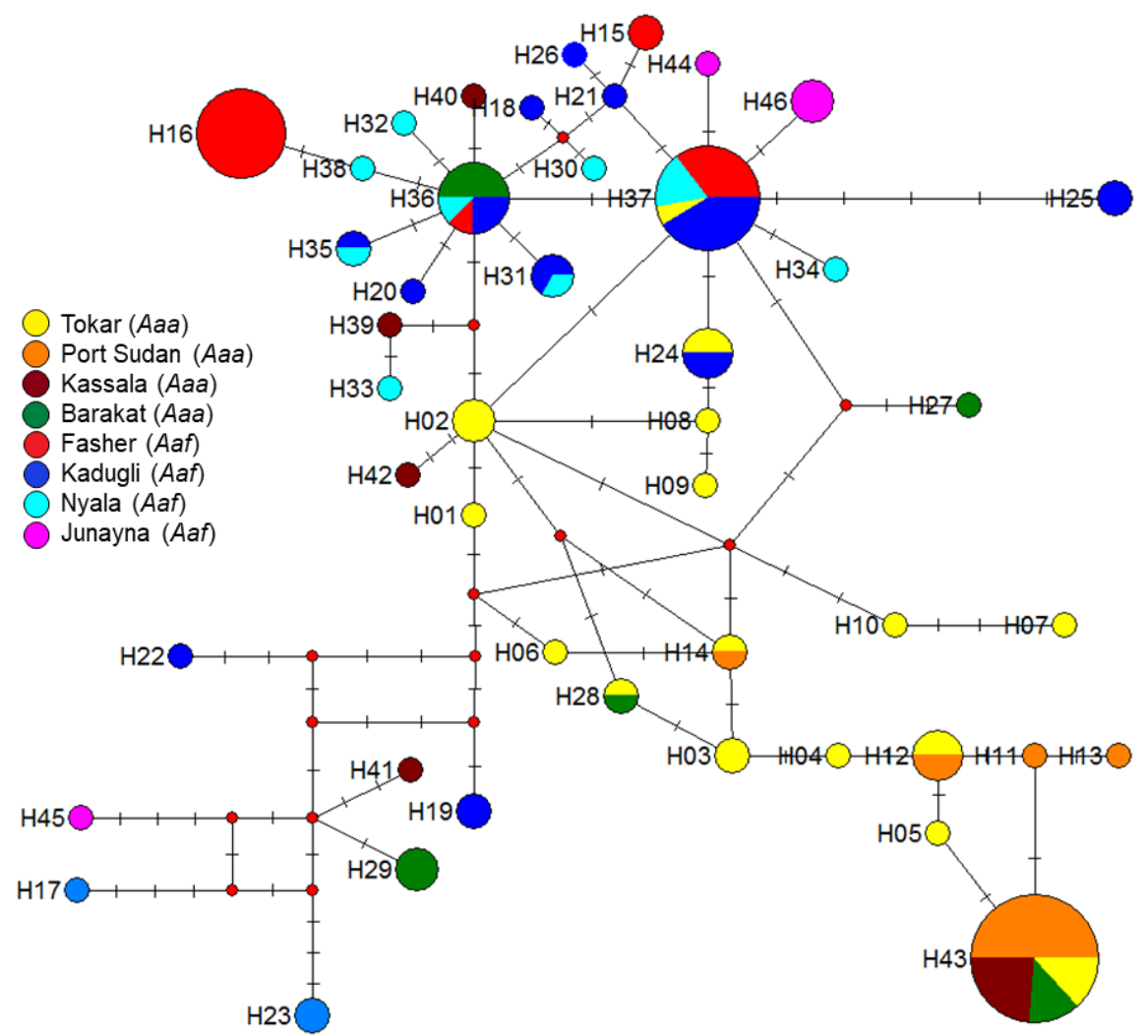

Figure 3. Polar maximum likelihood phylogenetic tree from 140 female Aedes aegypti aegypti (Aaa) and Aedes aegypti formosus (Aaf) form eight study sites in Sudan. Different colors indicate different subspecies/forms. Note most Aaa clustered in one group (blue colored), while Aaf clustered separately (red-colored). Exceptions to this were some Aaa from Tokar and Barakat clustered with Aaf populations.

Spatial analysis of molecular variance (SAMOVA) for population grouping also showed that the eight populations were grouped in three phylogeographically distinct groups/units. Group 1 includes Kadugli, Nyala, Al Fasher, and Al Junaynah Aaf populations. Group 2 consists of Port Sudan and Kassala Aaa populations. Group 3 consists of Barakat/Gezira and Tokar Aaa populations. Analysis of molecular variance (AMOVA) of the Aedes aegypti populations revealed $39.22 \%$ genetic variance among the three groups, and $53.53 \%$ within populations. (Table 5).

\subsection{Test of Neutrality and Natural Selection in Different Populations of Ae. aegypti}

We used Tajima's D and Fu's F tests to decipher deviations from neutrality owing to natural selection or population expansion in different populations of Ae. aegypti sampled in the study. The results of Tajima were found to be positive in the three sites of Tokar, Barakat/Gezira, and Al Fasher, indicating balancing natural selection or population substructuring; however, it was negative in Port Sudan, Kassala, Kadugli, Nyala, and Al Junaynah, indicating a recent directional selection or recent population growth. The results of the Fu's FS test were positive in Kassala, Barakat, Al Fasher, and Al Junaynah, which provides evidence indicating a recent population bottleneck or over-dominant selection, and negative in Port Sudan, Tokar, Kadugli, and Nyala, indicating a recent population expansion or genetic hitchhiking (Table 2). 


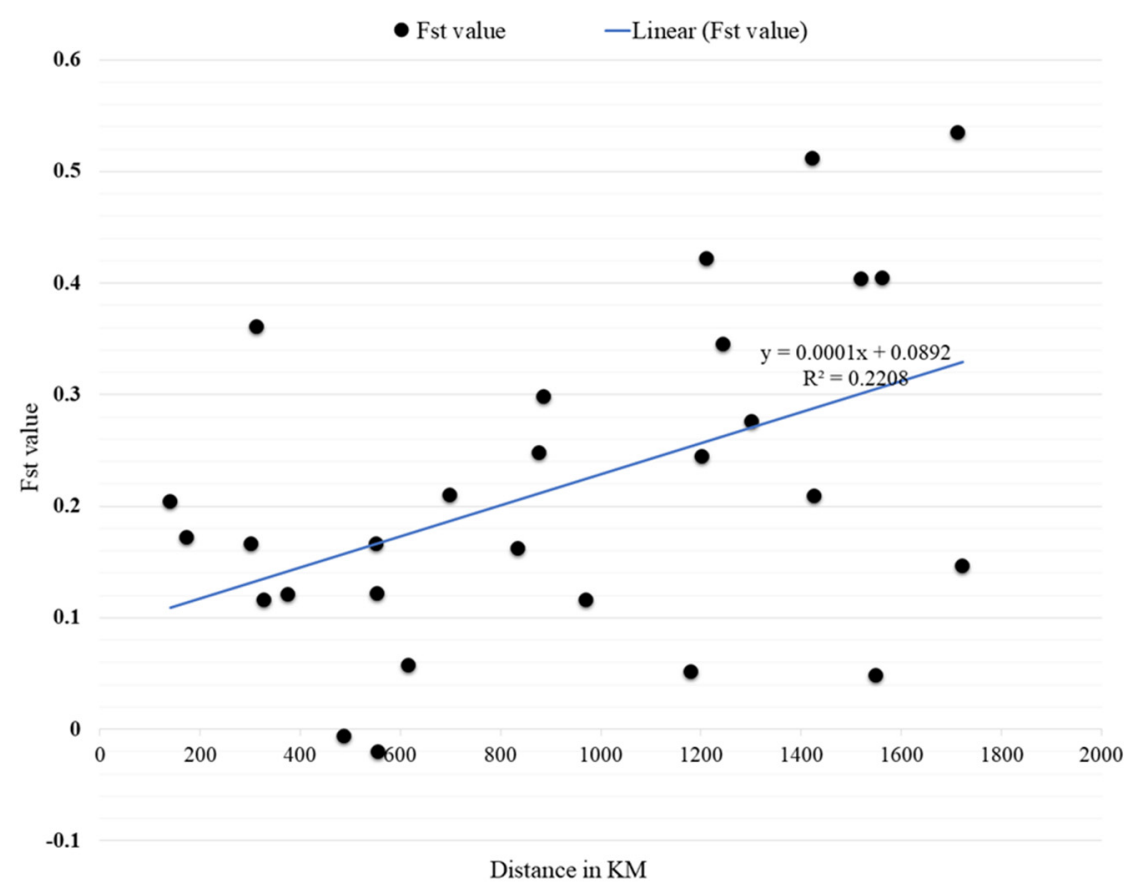

Figure 4. Results of the Mantel test on the correlation between genetic $\left(\mathrm{F}_{\mathrm{st}}\right)$ and geographical distances (KM) of Aedes aegypti samples collected in 8 locations in Sudan.

Table 5. Analysis of molecular variance (AMOVA) of three groups of Aedes aegypti collected from 8 sites in Sudan.

\begin{tabular}{ccccc}
\hline Source of Variation & df & Sum of Squares & $\begin{array}{c}\text { Variance } \\
\text { Components }\end{array}$ & $\begin{array}{c}\text { Percentage } \\
\text { of Variation }\end{array}$ \\
\hline Among Groups & 2 & 131.012 & 1.310 & 39.22 \\
Among Individuals within Groups & 5 & 27.672 & 0.243 & 7.26 \\
Within Populations & 131 & 234.244 & 1.788 & 53.53 \\
Total & 138 & 392.928 & 3.341 & \\
\hline
\end{tabular}

$\mathrm{df}=$ degree of freedom.

\section{Discussion}

The risk of emerging and re-emerging arthropod-borne viral (arboviral) infections is growing rapidly around the globe, particularly in the African continent [3]. Arboviral diseases have become a major health issue in Sudan. Over the last two decades, outbreaks of yellow fever, dengue, and chikungunya caused high mortality and morbidity in different parts of the country, particularly Port Sudan and Kassala in the east and Darfur in the west $[30,31,34,41]$. Ae. aegypti has been claimed as the principal vector of arboviruses responsible for these diseases. In Sudan, Aedes aegypti is reported to be the principal vector of yellow fever and dengue fever in different parts of the country, including Darfur, Kordofan, Port Sudan, and Kassala [26,28,30,33], However, there is a serious deficiency in recently published reports on the distribution and transmission of arboviruses by Aedes aegypti in different parts of Sudan. To our knowledge, this is the first published report on the distribution and genetic variations of Aedes aegypti subspecies/forms in different localities in the Sahelian belt of Sudan.

Despite the discovery that Aedes aegypti may exist as two morphologically distinct subspecies/forms, little is known about their relative contributions to the transmission of arboviral diseases in Africa [8]. Although reports showed that Aaf has less vector competence than Aaa, the vectorial capacity is a product of several attributes, including vector distribution, abundance, longevity, human-biting index, and tolerance of harsh 
environmental factors [15-17]. The current observations on the exclusive presence of Aaf and its apparent domestication and attachment to human dwellings in western Sudan indicate that Aaf might be the sole vector of arboviral diseases in this region. This notion supports the previous report by Lewis who stated that under conditions of urbanization, ssp. formosus can become very largely domesticated and can have an increased contribution to the transmission of human arboviruses $[8,25]$. Similarly, Futami observed that the two subspecies were sympatric in both artificial and natural containers, suggesting adaptation of Aaf to various habitats [42]. Interestingly, in west Africa, a group of researchers found that populations of Aaf can be competent transmitters of Flaviviruses [15]. Although knowledge of the vector competence in the two subspecies is a crucial component in arbovirus epidemiology and control, research on this aspect has been extremely limited. Further work is, therefore, needed to compare the survival, fecundity, and human-biting index and vector competence of the two subspecies.

Our results show that both subspecies of Ae. aegypti are found in the Sahelian belt of Sudan. No previous publications showed similar results clearly, as the reported literature did not address the distinction between the two subspecies/forms of Aedes aegypti in the country. However, in the older literature, Mattingly reported that Lewis found a dark form in Erkawiet in eastern Sudan and stated that, in personal communication, Lewis informed him that this specimen was likely an Ae. aegypti formosus subspecies [8]. The lack of distinction between the two forms is also an apparent feature of the literature from neighboring Sahelian countries, as no recent records on the differentiation of Ae. aegypti aegypti and Ae. aegypti formosus were reported from Eritrea, Ethiopia, Chad, and Central Africa Republic [12,13,15,42].

We found an interesting difference in the distribution of the two subspecies of Aedes aegypti in Sudan; Aedes aegypti aegypti, found in four study sites east of the Nile river, i.e., eastern and central Sudan, and Aedes aegypti formosus in the other four sites in the west. Although the Nile and the White Nile appeared to show a clear demarcation of the location of the Ae. aegypti aegypti and Ae. aegypti formosus, it is unlikely that these river systems provide true geographical barriers for the two subspecies. A possible explanation for this distribution may be offered by the contrasting soil and different ecological parameters. Despite sharing similar latitudes and rainfall patterns, eastern and western Sudan have marked differences in soil that affect water retention, moisture, and maximum temperature and humidity [43,44]. In eastern Sudan, the soil is mainly chromic vertisols deposited by previous volcanic activities in the Ethiopian Plateau. This soil is highly hydrophobic, losing moisture quickly after the end of the rainy season and thus resulting in higher maximum temperature, lower humidity, and lower annual NDVI (Normalized Vegetation Index) values. In contrast, the sandy soil of western Sudan has higher retention of moisture, resulting in higher lower max temperature, higher humidity, and higher NDVI value [43,44].

In this study, we did not encounter the sympatric presence of the two subspecies/forms of Aedes aegypti. However, the possibility of the sympatric presence of the two subspecies cannot be ruled out, since our study was not exhaustive enough and was limited by several logistical barriers. In other locations in Africa, different authors reported contrasting findings on the distribution of the two forms. Mattingly stated that the Ae. a. formosus was recorded in natural breeding sites in the forests or bush away from human dwellings in Kenya and Uganda [8]. On the other hand, Gloria-Soria mentioned two different distribution cases in Kenya. In one of these cases, populations of the two subspecies/forms were sympatric and freely mixed in Mombasa/Kenya. In the other case, in a geographically closely related site, they found that Aaf was restricted to the African forest, while Aaa was present in domestic habitats [14].

We found a relatively high genetic variation and structuring between different populations of Aaa and Aaf in Sudan. In the polar phylogenetic tree, two subspecies are clustered in two distinct groups with only three haplotypes shared between them. These results were further confirmed by SAMOVA analysis which separated the Aaf populations in one group while splitting the Aaa populations into two similar groups. Furthermore, the 
divergence between Aaf and Aaa populations was revealed in high $\mathrm{F}_{\mathrm{ST}}$ values between the two subspecies, for example in the Port Sudan and Al Fasher sites $\left(\mathrm{F}_{\mathrm{ST}}=0.848\right)$.

Although all genetic variation indices of the mitochondrial gene cytochrome-oxidase 1 (CO1) revealed low gene flow between the two subspecies in Sudan and high genetic diversity between their populations, it is difficult to conclude whether this variation reflects a true difference between the two subspecies or the geographical distances that limited the gene flow. Other researchers, using microsatellite markers on sympatric and allopatric populations of Aedes aegypti, concluded that the two subspecies/forms are genetically distinct [14]. It may be hypothesized that possible gene flow between the two subspecies originated recently after the encroachment of the Aaf into the human habitat where the Aaa was already found. Using genetic data, Powell concluded that there was total isolation and lack of gene flow between the two subspecies about 400-550 years ago [45].

Our results contrast with the findings of Powell and Tabachnick [18], who reported that Aaf subspecies have less genetic variation than the Aaa subspecies. In our studies, we found that both subspecies have similarly high genetic variations. The difference between our results and the findings of [13] and [18] may be due to the ecological conditions. Our collection sites of Aaf populations were generally more arid than the sites of these authors. Coupled with the large geographic distances between our study sites, the high aridity limits the movement and gene flow between the populations.

It was evident that the level of genetic variation of Aedes aegypti populations was different in different sites. The lowest variation was observed in the Aaa population in the coastal city, Port Sudan. Similar results were reported by Elnour [29], who reported the presence of four haplotypes of mitochondrial CO1 gene in Aedes aegypti populations in Port Sudan. This lower genetic variation in Port Sudan may be due to the fact that the Red Sea provides consistent high humidity throughout the year, thus reducing the impact of dryness on the vector population. In contrast, other sites in the country had a higher impact of natural selection, as predicted by Tajima D and Fu's Fs statistics.

In conclusion, our results show that both subspecies of Aedes aegypti are found in Sudan, with clear variation in their distribution. Whereas the Aaa subspecies appears to be more abundant in the eastern part of the country, the Aaf subspecies is the main form of the vector found in western Sudan. There was a clear distinction in the genetic structure of the two subspecies. Further work is urgently required to elucidate the role of each subspecies in the transmission of dengue fever, chikungunya, yellow fever, and other arboviruses in Sudan and other countries of the African Sahelian region. Furthermore, work is needed to understand the ecological determinants of the distribution of the two subspecies and develop suitable control programs for the viruses they transmit.

\section{Methods}

\subsection{Study Sites}

Mosquitoes were collected from eight study sites in Sudan, where dengue and other arboviral disease outbreaks were reported. As shown in Figure 1, the sites consisted of Port Sudan (Red Sea state), Kassala (Kassala state), Tokar (Red sea state), Barakat (Gezira state), Kadugli (South Kordofan state), Al Fashir (North Darfur state), Nyala (South Darfur state) and Al Junaynah (West Darfur state).

Seven of the study sites (Kassala, Tokar, Barakat, Kadugli, Nyala, Al Fashir, and Al Junaynah) have a tropical continental climate, characterized by a long ( 9 month) dry season between October and June and a short rainy season between July and September. The eighth site (Port Sudan), located on the coast of the Red Sea, has a hot desert climate with high levels of humidity and a short rainy season during the cooler months of November to February [43].

Apart from Barakat, all study sites have a consistent history of dengue fever, which results in more frequent outbreaks in Port Sudan, Tokar, and Kassala. Other major arboviral diseases in the study sites are yellow fever in Kadugli, Al Fashir, Nyala and Al Junaynah, and chikungunya, which was recently reported in all areas of the country. 


\subsection{Mosquito Collection, Rearing, and Morphological Identification}

Immature stages of Aedes mosquitoes (eggs, larvae, and pupae) were collected from their natural habitats indoors and outdoors in all the study sites throughout (January 2014-April 2017). Different breeding sites were surveyed. The samples were transferred to the insectary at the Sudan national public health laboratory for rearing at the optimum temperature $\left(25 \pm 2{ }^{\circ} \mathrm{C}\right)$ and relative humidity $(80-90 \%)$ with a photoperiod of $12: 12$ (L:D) until the adults emerged. Samples from each collection were morphologically identified to their species using appropriate taxonomic keys [46]. After the adult's emergence, Aedes aegypti females and males were classified into their subspecies/forms, either Aaa or Aaf, according to the appropriate morphological key, depending on the scale pattern system [47]. The mosquitoes with white scales on the first abdominal tergite were classified as Aaa form, while adults that possessed white scales in the first abdominal tergite were classified as Aaf form. Female mosquitoes of Aaa and Aaf from different sites were preserved individually in labelled microfuge tubes with $70 \%$ isopropanol and then kept in a $-20{ }^{\circ} \mathrm{C}$ freezer. Preserved samples were transferred to the Universiti Sains Malaysia (USM) where the DNA extraction was performed.

\subsection{DNA Extraction and Molecular Identification}

Genomic DNA was extracted from single female mosquitoes using Qiagen DNeasy Blood and Tissue Extraction Kit (Qiagen, Hilden, Germany) following the manufacturer's instructions with slight modifications in extending the incubation period to overnight at $65{ }^{\circ} \mathrm{C}$. Extracted DNA was eluted in nuclease-free water and preserved in a $-20^{\circ} \mathrm{C}$ freezer until use. The DNA quantity and quality for all extracted samples were checked using Nanodrop Quawell UV spectrophotometer Q3000. Further confirmation of species identification was executed using internal transcribed spacer region 1 (ITS1) using forward primer ITS1A, 5 -CCT TTG TAC ACA CCG CCC GTC G-3, and reverse primer ITS1B, 5-ATG TGT CCT GCA GTT CAC A-3 described by [48] with modification in the cycling condition of $95{ }^{\circ} \mathrm{C}$ for $2 \mathrm{~min}$ followed by 40 cycles of $95^{\circ} \mathrm{C}$ for $45 \mathrm{~s}, 53^{\circ} \mathrm{C}$ for $40 \mathrm{~s}, 72{ }^{\circ} \mathrm{C}$ for $10 \mathrm{~min}$ and final extension of $72{ }^{\circ} \mathrm{C}$ for $5 \mathrm{~min}$. Gel electrophoresis was performed on $1.2 \%$ agarose gel in Tris-acetate-EDTA buffer (TAE). PCR products containing DNA fragments were further digested by restriction analysis by taking $10 \mu \mathrm{L}$ of the PCR product in a microfuge tube, $5 \mu \mathrm{L}$ of $10 \times$ Rsal buffer, and $1 \mathrm{U} / 1 \mu \mathrm{L}$ of Rsal enzyme per reaction (NEB II, New England Biolabs). After mixing, the tubes were incubated at $37^{\circ} \mathrm{C}$ for $2 \mathrm{~h}$ and then separated on a 3.0\% agarose gel stained with Red Safe TM Nucleic Acid Staining Solution (INTRON Biotechnology, Seongnam, Korea), and ran at $100 \mathrm{~V}$ for $30 \mathrm{~min}$. The gel was viewed under UV light, and the photo was captured to determine the pattern of the fragment DNA segments following [48].

\subsection{PCR Amplification for Mitochondrial Marker}

Cytochrome oxidase 1 mitochondrial marker was used to detect polymorphisms among the different populations; a minimum of 10 mosquito samples from each site were tested (Table 1). Partial CO1 gene was amplified using primer pair (COI-F) 5'TGTAATTGTAACAGCTCATGCA-3' and (COI-R) 5'-AATGATCATAGAAGGGCT GGAC$3^{\prime}$, mixed in $50 \mu \mathrm{L}$ reaction volume containing $10 \mu \mathrm{L}$ of $10 \times$ Green Buffer Go Taq (Promega, Madison, WI, USA), $3 \mu \mathrm{L}$ of $25 \mathrm{mM} \mathrm{MgCl}_{2}, 1 \mu \mathrm{L}$ of $25 \mathrm{mM}$ dNTP, $0.3 \mu \mathrm{M}$ from each primer, $0.5 \mu \mathrm{L}$ of Taq polymerase and $2 \mu \mathrm{L}$ (>50 ng) from the sample DNA [49]. The thermal cycling conditions were configured as the first denaturation step at $94{ }^{\circ} \mathrm{C}$ for $2 \mathrm{~min}$, followed by 35 cycles at $94{ }^{\circ} \mathrm{C}$ for $1 \mathrm{~min}, 54{ }^{\circ} \mathrm{C}$ for $30 \mathrm{~s}$, and $72{ }^{\circ} \mathrm{C}$ for $1 \mathrm{~min}$, and a final extension of $72{ }^{\circ} \mathrm{C}$ for $10 \mathrm{~min}$. PCR products were separated on a $1.5 \%$ agarose gel electrophoresis in Tris-borate-EDTA buffer (TBE) for one hour, a 100 bp DNA ladder was used as a marker, and the agarose gel was stained with Red Safe dye. Then, the gel was viewed under UV light using the gel documentation system. PCR-amplified samples were purified from the agarose gel using a Qiagen purification kit following the manufacturer protocol [49]. 
The cleaned PCR products were chosen, isolated, and sent to Apical sequencing services (Kuala Lumpur, Malaysia) for the Sanger DNA sequencing process. The sequencing services were done with the ABI 3130XL automatic sequencer (Applied Biosystem, Foster City, CA, USA).

\subsection{Mitochondrial Sequences Analyses}

Sequences were generated and checked manually by using Molecular Evolutionary Genetics Analysis software MEGA v7.0 [50] and compared to the previously published sequences in the Genbank database using the Basic Local Alignment Search Tool (BLAST, https://blast.ncbi.nlm.nih.gov / Blast.cgi). The nucleotides obtained were aligned by using the sequence alignment tool ClustalW in the MEGA. Sequences were translated to amino acids (invertebrate mitochondrial code) to check for unexpected stop codons or frameshift mutations implemented in the same software.

Unique haplotypes in the aligned matrix for both forms of Aedes aegypti were determined using DNAsp 5.10.1 [51] and were deposited in GenBank with the accession numbers MT193027 to MT193072.

\subsection{Phylogenetic Analyses/Trees}

The relationship between individuals of all population studies was illustrated using polar unrooted maximum-likelihood phylogenetic trees built using IQ-TREE 1.6.9 [52] and shaped using Figtree v1.4.0 [53]. The best model was found to be HKY+F+I using Model Finder [54]. Relationships between the different haplotypes in the eight sites from the two forms located in the different study sites were displayed using median-joining haplotype networks. Haplotype networks were drawn using NETWORK 10.00 [55].

\subsection{Genetic Diversity and Genetic Structure of Aedes aegypti Subspecies}

Standard molecular diversity indices-the number of haplotypes per locality (h), the number of variable sites (S), haplotype diversity $(\mathrm{Hd})$, and nucleotide diversity $(\pi)$-were estimated within Aaa and Aaf populations using Arlequin v3.5 [56].

Genetic diversity and molecular variance of the populations assessed using Analyses of Molecular Variance (AMOVA) in Arlequin v3.5 [56]. The pairwise genetic distances ( $\mathrm{F}_{\mathrm{ST}}$ ) were estimated between the different populations and their significance.

Geographical distances between the different study sites were approximated using a ruler tool in Google Earth TM (Google Inc., Mountain View, CA, USA). Genetic isolation by distance (IBD) was assessed using pairwise geographical distance and was matched to pairwise $\mathrm{F}_{\mathrm{ST}}$ in the different haplotypes independently to obtain a linear regression relationship. The Mantel test was carried out to prove the significance of the association between genetic variations and geographical distance between study sites using Arlequin v3.5 [56].

The genetic structure was estimated using Spatial Analyses of Molecular Variance (SAMOVA), SAMOVA v2.0 [57], to interpret the genetic barriers on population groups after the best-fit grouping pattern was estimated. The method classified the populations that were geographically similar and excellently separated the groups with the highest $\mathrm{F}_{\mathrm{CT}}$ (diversity between groups) while the lowest $\mathrm{F}_{\mathrm{SC}}$ (diversity among populations within a group) were considered the most possible populations grouping. Since the $\mathrm{F}_{\mathrm{CT}}$ values in the study were found to have no significant difference, other methods were used following [58]. The $\mathrm{F}_{\mathrm{CT}}$ (genetic differentiation among groups) was found to be relatively stable with very low differences; nevertheless, $\mathrm{F}_{\mathrm{SC}}$ (genetic differentiation between individuals within such groups) revealed a noticeable decrease from two to three clusters of groups); from this, we conclude that the best grouping (best homogeneity among groups) is three-group clustering.

After that, SAMOVA structuring results were used to estimate the genetic molecular variance using Analyses of Molecular Variance (AMOVA) in Arlequin v3.5 [56]. 
Tajima's D and Fu's F statistics were used to detect deviation from neutrality and population expansion using Arlequin v3.5 [56].

Author Contributions: Conceptualization: S.A.A., D.E.E., H.M.A., and Z.J.; sample and data collection: S.A.A. and K.N.; data analysis: S.A.A., J.A.F.J., and M.A.; funding acquisition: S.A.A., Z.J,, M.F.F.W., I.H.I., and N.F.A.K.; methodology: S.A.A.; writing—original draft: S.A.A.; critical Editing of the draft: S.A.A. and D.E.E.; review of the manuscript: M.F.F.W., H.M.A., J.A.F.J., M.A., and D.E.E. All authors have read and agreed to the published version of the manuscript.

Funding: This research received a research university grant of Universiti Sains Malaysia (1001/PBIOLOGI/8011032).

Institutional Review Board Statement: Not applicable.

Informed Consent Statement: Not applicable.

Data Availability Statement: Data is contained within the article.

Acknowledgments: The authors gratefully acknowledge Universiti Sains Malaysia for support through a research grant (1001/PBIOLOGI/8011032). Gratitude to the Organization for Women in Science for the Developing World (OWSD) for providing scholarship opportunity to Sara Abuelmaali. The support for this study was also given by the Sudan Federal Ministry of Health, Sudan for facilitating the data collections.

Conflicts of Interest: The authors declare no conflict of interest.

\section{References}

1. Kraemer, M.U.; E Sinka, M.; A Duda, K.; Mylne, A.Q.N.; Shearer, F.M.; Barker, C.M.; Moore, C.G.; Carvalho, R.G.; E Coelho, G.; Van Bortel, W.; et al. The global distribution of the arbovirus vectors Aedes aegypti and Ae. albopictus. eLife 2015, 4, e08347. [CrossRef] [PubMed]

2. Souza-Neto, J.A.; Powell, J.R.; Bonizzoni, M. Aedes aegypti vector competence studies: A review. Infect Genet Evol. 2019, 67, 191-209. [CrossRef] [PubMed]

3. Weetman, D.; Kamgang, B.; Badolo, A.; Moyes, C.L.; Shearer, F.M.; Coulibaly, M.B.; Pinto, J.; Lambrechts, L.; McCall, P. Aedes Mosquitoes and Aedes-Borne Arboviruses in Africa: Current and Future Threats. Int. J. Environ. Res. Public Health 2018, 15, 220. [CrossRef] [PubMed]

4. Kamal, M.; Kenawy, M.A.; Rady, M.H.; Khaled, A.S.; Samy, A.M. Mapping the global potential distributions of two arboviral vectors Aedes aegypti and Ae. albopictus under changing climate. PLoS ONE 2018, 13, e0210122. [CrossRef] [PubMed]

5. Kweka, E.J.; Baraka, V.; Mathias, L.; Mwang'onde, B.; Baraka, G.; Lyaruu, L.; Mahande, A.M. Ecology of Aedes Mosquitoes, the Major Vectors of Arboviruses in Human Population. In Dengue Fever-A Resilient Threat in the Face of Innovation; Abelardo Falcón-Lezama, J., Betancourt-Cravioto, M., Tapia-Conyer, R., Eds.; IntechOpen: London, UK, 2019; Available online: https://www.intechopen.com/books/dengue-fever-a-resilient-threat-in-the-face-of-innovation/ecology-of-aedesmosquitoes-the-major-vectors-of-arboviruses-in-human-population (accessed on 9 November 2020).

6. Morrison, A.C.; Zielinski-Gutierrez, E.; Scott, T.W.; Rosenberg, R. Defining Challenges and Proposing Solutions for Control of the Virus Vector Aedes aegypti. PLoS Med. 2008, 5, e68. [CrossRef]

7. Scott, T.W.; Takken, W. Feeding strategies of anthropophilic mosquitoes result in increased risk of pathogen transmission. Trends Parasitol. 2012, 28, 114-121. [CrossRef]

8. Mattingly, P.F. Genetical Aspects of the Aëdes Aegypti Problem: I.-Taxonomy and Bionomics. Ann. Trop. Med. Parasitol. 1957, 51, 392-408. [CrossRef]

9. McBride, C.S.; Baier, F.; Omondi, A.B.; Spitzer, S.A.; Lutomiah, J.; Sang, R.; Ignell, R.; Vosshall, L.B. Evolution of mosquito preference for humans linked to an odorant receptor. Nat. Cell Biol. 2014, 515, 222-227. [CrossRef]

10. Lewis, D.J. The Aëdes Mosquitoes of the Sudan. Ann. Trop. Med. Parasitol. 1955, 49, 164-173. [CrossRef]

11. Lewis, D.J. Observations on the distribution and taxonomy of culicidae (diptera) in the sudan. Trans. R. Entomol. Soc. Lond. 2009, 95, 1-24. [CrossRef]

12. Paupy, C.; Brengues, C.; Ndiath, O.; Toty, C.; Hervé, J.-P.; Simard, F. Morphological and genetic variability within Aedes aegypti in Niakhar, Senegal. Infect. Genet. Evol. 2010, 10, 473-480. [CrossRef] [PubMed]

13. Brown, J.E.; McBride, C.S.; Johnson, P.; Ritchie, S.; Paupy, C.; Bossin, H.; Lutomiah, J.; Fernandez-Salas, I.; Ponlawat, A.; Cornel, A.J.; et al. Worldwide patterns of genetic differentiation imply multiple 'domestications' of Aedes aegypti, a major vector of human diseases. Proc. R. Soc. B Boil. Sci. 2011, 278, 2446-2454. [CrossRef] [PubMed]

14. Gloria-Soria, A.; Ayala, D.; Bheecarry, A.; Calderon-Arguedas, O.; Chadee, D.D.; Chiappero, M.; Coetzee, M.; Bin Elahee, K.; Fernandez-Salas, I.; Kamal, H.A.; et al. Global genetic diversity ofAedes aegypti. Mol. Ecol. 2016, 25, 5377-5395. [CrossRef] [PubMed] 
15. Captain-Esoah, M.; Baidoo, P.K.; Frempong, K.K.; Adabie-Gomez, D.; Chabi, J.; Obuobi, D.; Amlalo, G.K.; Veriegh, F.B.; Donkor, M.; Asoala, V.; et al. Biting Behavior and Molecular Identification of Aedes aegypti (Diptera: Culicidae) Subspecies in Some Selected Recent Yellow Fever Outbreak Communities in Northern Ghana. J. Med. Entomol. 2020, 57, 1239-1245. [CrossRef]

16. Black, W.C.; Bennett, K.E.; Gorrochótegui-Escalante, N.; Barillas-Mury, C.V.; Fernández-Salas, I.; de Lourdes Muñoz, M.; Farfán-Alé, J.A.; Olson, K.E.; Beaty, B.J. Flavivirus Susceptibility in Aedes aegypti. Arch. Med. Res. 2002, 33, 379-388. [CrossRef]

17. Dickson, L.B.; Sanchez-Vargas, I.; Sylla, M.; Fleming, K.; Black, W.C. Vector Competence in West African Aedes aegypti Is Flavivirus Species and Genotype Dependent. PLoS Negl. Trop. Dis. 2014, 8, e3153. [CrossRef]

18. Powell, J.R.; Tabachnick, W.J. History of domestication and spread of Aedes aegypti-A Review. Memórias Inst. Oswaldo Cruz 2013, 108 (Suppl. 1), 11-17. [CrossRef]

19. Tabachnick, W.J.; Powell, J.R. A world-wide survey of genetic variation in the yellow fever mosquito, Aedes aegypti. Genet. Res. 1979, 34, 215-229. [CrossRef]

20. Rašić, G.; Schama, R.; Powell, R.; Maciel-de Freitas, R.; Endersby-Harshman, N.M.; Filipović, I.; Sylvestre, G.; Máspero, R.C.; Hoffmann, A.A. Contrasting genetic structure between mitochondrial and nuclear markers in the dengue fever mosquito from Rio de Janeiro: Implications for vector control. Evol. Appl. 2015, 8, 901-915. [CrossRef]

21. Sousa, A.A.D.; Fraga, E.; Sampaio, I.; Schneider, H.; Barros, M.C. Genetic differentiation in populations of Aedes aegypti (Diptera, Culicidae) dengue vector from the Brazilian state of Maranhão. Rev. Bras. Entomol. 2017, 61, 51-59. [CrossRef]

22. Crawford, J.E.; Alves, J.M.; Palmer, W.J.; Day, J.P.; Sylla, M.; Ramasamy, R.; Surendran, S.N.; Iv, W.C.B.; Pain, A.; Jiggins, F.M. Population genomics reveals that an anthropophilic population of Aedes aegypti mosquitoes in West Africa recently gave rise to American and Asian populations of this major disease vector. BMC Biol. 2017, 15, 16. [CrossRef] [PubMed]

23. Joyce, A.L.; Torres, M.M.; Torres, R.; Moreno, M. Genetic variability of the Aedes aegypti (Diptera: Culicidae) mosquito in El Salvador, vector of dengue, yellow fever, chikungunya and Zika. Parasites Vectors 2018, 11, 637. [CrossRef]

24. Naim, D.M.; Kamal, N.Z.M.; Mahboob, S. Population structure and genetic diversity of Aedes aegypti and Aedes albopictus in Penang as revealed by mitochondrial DNA cytochrome oxidase I. Saudi J. Biol. Sci. 2020, 27, 953-967. [CrossRef] [PubMed]

25. Lewis, D.J. TheStegomyiaMosquitoes of the Anglo-Egyptian Sudan. Ann. Trop. Med. Parasitol. 1953, 47, 51-61. [CrossRef] [PubMed]

26. Lewis, D.J. Mosquitoes in Relation to Yellow Fever in the Nuba Mountains, Anglo-Egyptian Sudan. Ann. Trop. Med. Parasitol. 1943, 37, 65-76. [CrossRef]

27. Ahmed, A.; Elduma, A.H.; Magboul, B.; Higazi, T.B.; Ali, Y. The First Outbreak of Dengue Fever in Greater Darfur, Western Sudan. Trop. Med. Infect. Dis. 2019, 4, 43. [CrossRef]

28. Ahmed, R.M.H. Breeding and Resting Behaviour of Aedes aegypti in Indoor and Outdoor Environment in Kassala City, Sudan 2014/2015. Health Sci. J. 2019, 13, 10.

29. Elnour, M.B.; Moustafa, M.A.M.; Khogali, R.; Azrag, R.S.; Alanazi, A.D.; Kheir, A.; Nakao, R.; De Meeûs, T.; Salim, B. Distinct haplotypes and free movement of Aedes aegypti in Port Sudan, Sudan. J. Appl. Entomol. 2020, 144, 817-823. [CrossRef]

30. Ahmed, A.; Dietrich, I.; LaBeaud, A.D.; Lindsay, S.W.; Musa, A.M.; Weaver, S.C. Risks and Challenges of Arboviral Diseases in Sudan: The Urgent Need for Actions. Viruses 2020, 12, 81. [CrossRef]

31. Himatt, S.; Osman, K.E.; Okoued, S.I.; Seidahmed, O.E.; Beatty, M.E.; Soghaier, M.A.; Elmusharaf, K. Sero-prevalence of dengue infections in the Kassala state in the eastern part of the Sudan in 2011. J. Infect. Public Health 2015, 8, 487-492. [CrossRef]

32. Rm, A.; Sm, H.; Ah, E. Climatic Factors Affecting Density of Aedes aegypti (Diptera: Culicidae) in Kassala City, Sudan 2014/2015. Asploro J. Biomed. Clin. Case Rep. 2019, 2, 58-68. [CrossRef]

33. Soghaier, M.A.; Hagar, A.; Abbas, M.A.; Elmangory, M.M.; Eltahir, K.M.; Sall, A.A. Yellow Fever outbreak in Darfur, Sudan in October 2012; the initial outbreak investigation report. J. Infect. Public Health 2013, 6, 370-376. [CrossRef] [PubMed]

34. Seidahmed, O.M.E.; Siam, H.A.M.; Soghaier, M.A.; Abubakr, M.; Osman, H.A.; Elrhman, L.S.A.; Elmagbol, B.; Velayudhan, R. Dengue vector control and surveillance during a major outbreak in a coastal Red Sea area in Sudan. East Mediterr. Health J. 2012, 18, 8. [CrossRef]

35. Soghaier, M.A.; Abdelgadir, D.M.; Abdelkhalig, S.M.; Kafi, H.; Zarroug, I.M.A.; A Sall, A.; Eldegai, M.H.; Elageb, R.M.; Osman, M.M.; Khogali, H. Evidence of pre-existing active Zika virus circulation in Sudan prior to 2012. BMC Res. Notes 2018, 11, 906. [CrossRef] [PubMed]

36. Ahmed, A. Urgent call for a global enforcement of the public sharing of health emergencies data: Lesson learned from serious arboviral disease epidemics in Sudan. Int. Health 2020, 12, 238-240. [CrossRef]

37. Gould, L.H.; Osman, M.S.; Farnon, E.C.; Griffith, K.S.; Godsey, M.S.; Karch, S.; Mulenda, B.; El Kholy, A.; Grandesso, F.; De Radiguès, X.; et al. An outbreak of yellow fever with concurrent chikungunya virus transmission in South Kordofan, Sudan, 2005. Trans. R. Soc. Trop. Med. Hyg. 2008, 102, 1247-1254. [CrossRef]

38. Adam, A.; Seidahmed, O.M.; Weber, C.; Schnierle, B.; Schmidt-Chanasit, J.; Reiche, S.; Jassoy, C. Low Seroprevalence Indicates Vulnerability of Eastern and Central Sudan to Infection with Chikungunya Virus. Vector-Borne Zoonotic Dis. 2016, 16, 290-291. [CrossRef]

39. Bushra, H.E.E.; Habtewold, B.W.; Gasseer, N.A.; Mohamed, R.E.; Mohamednour, S.A.; Abshar, M.; Al Magboul, B. Outbreak of Chikungunya Fever in Sudan, 2018-2019. JOJ Pub Health. 2019, 4, 555644.

40. Bracco, J.E.; Capurro, M.L.; Lourenço-De-Oliveira, R.; Sallum, M.A.M. Genetic variability of Aedes aegypti in the Americas using a mitochondrial gene: Evidence of multiple introductions. Memórias Inst. Oswaldo Cruz 2007, 102, 573-580. [CrossRef] 
41. Ahmed, A.; Ali, Y.; Elmagboul, B.; Mohamed, O.; Elduma, A.; Bashab, H.; Mahamoud, A.; Khogali, H.; Elaagip, A.; Higazi, T. Dengue Fever in the Darfur Area, Western Sudan. Emerg. Infect Dis. 2019, 25, 2126. [CrossRef]

42. Futami, K.; Iwashita, H.; Higa, Y.; A Lutiali, P.; O Sonye, G.; Mwatele, C.; Njenga, S.M.; Minakawa, N. Geographical Distribution of Aedes aegypti aegypti and Aedes aegypti formosus (Diptera: Culicidae) in Kenya and Environmental Factors Related to Their Relative Abundance. J. Med. Entomol. 2019, 57, 772-779. [CrossRef] [PubMed]

43. Thomson, M.C.; Elnaiern, D.A.; Ashford, R.W.; Connor, S.J. Towards a kala azar risk map for Sudan: Mapping the potential distribution of Phlebotomus orientalis using digital data of environmental variables. Trop. Med. Int. Health 1999, 4, 105-113. [CrossRef] [PubMed]

44. Elnaiem, D.A.; Hassan, H.K.; Ward, R.D. Associations of Phlebotomus orientalis and other sandflies with vegetation types in the eastern Sudan focus of kala-azar. Med. Vet. Entomol. 1999, 13, 198-203. [CrossRef] [PubMed]

45. Powell, J.R.; Gloria-Soria, A.; Kotsakiozi, P. Recent History of Aedes aegypti: Vector Genomics and Epidemiology Records. BioScience 2018, 68, 854-860. [CrossRef] [PubMed]

46. Hopkins, G.H.E. Mosquito of the Ethiopian Region, 2nd ed.; British Museum (NATURAL HISTORY), CROMWELL ROAD, S.W.7; 1952; Available online: http:/ / mosquito-taxonomic-inventory.info/sites/mosquito-taxonomic-inventory.info/files/Hopkins\% 201952.pdf (accessed on 24 February 2011).

47. Huang, Y.-M. The subgenus Stegomyia of Aedes in the Afrotropical Region with keys to the species (Diptera: Culicidae). Zootaxa 2004, 700, 1. [CrossRef]

48. Beebe, N.W.; Whelan, P.I.; Corcoran, S.; Cooper, R.D. A Polymerase Chain Reaction-Based Diagnostic to Identify Larvae and Eggs of Container Mosquito Species from the Australian Region. J. Med. Entomol. 2007, 44, 5. [CrossRef]

49. Paupy, C.; Le Goff, G.; Brengues, C.; Guerra, M.; Revollo, J.; Simon, Z.B.; Hervé, J.-P.; Fontenille, D. Genetic structure and phylogeography of Aedes aegypti, the dengue and yellow-fever mosquito vector in Bolivia. Infect Genet Evol. 2012, 12, 1260-1269. [CrossRef]

50. Kumar, S.; Stecher, G.; Tamura, K. MEGA7: Molecular Evolutionary Genetics Analysis Version 7.0 for Bigger Datasets. Mol. Biol. Evol. 2016, 33, 1870-1874. [CrossRef]

51. Librado, P.; Rozas, J. DnaSP v5: A software for comprehensive analysis of DNA polymorphism data. Bioinformatics 2009, 25, 1451-1452. [CrossRef]

52. Nguyen, L.-T.; Schmidt, H.A.; Von Haeseler, A.; Minh, B.Q. IQ-TREE: A Fast and Effective Stochastic Algorithm for Estimating Maximum-Likelihood Phylogenies. Mol. Biol. Evol. 2015, 32, 268-274. [CrossRef]

53. Rambaut, A. FigTree. 2012. Available online: https:/ / github.com/rambaut/figtree/releases (accessed on 26 November 2018).

54. Kalyaanamoorthy, S.; Minh, B.Q.; Wong, T.K.F.; Von Haeseler, A.; Jermiin, L.S. ModelFinder: Fast model selection for accurate phylogenetic estimates. Nat. Methods 2017, 14, 587-589. [CrossRef] [PubMed]

55. Bandelt, H.J.; Forster, P.; Rohl, A. Median-joining networks for inferring intraspecific phylogenies. Mol. Biol. Evol. 1999, 16, 37-48. [CrossRef] [PubMed]

56. Excoffier, L.; Lischer, H.E.L. Arlequin suite ver 3.5: A new series of programs to perform population genetics analyses under Linux and Windows. Mol. Ecol. Resour. 2010, 10, 564-567. [CrossRef] [PubMed]

57. Dupanloup, I.; Schneider, S.; Excoffier, L. A simulated annealing approach to define the genetic structure of populations: Defining the genetic structure of populations. Mol. Ecol. 2002, 11, 2571-2581. [CrossRef] [PubMed]

58. Byron, V. Weckworth NJD Mark Hebblewhite, Marco Musiani. Genetic Analysis of Caribou Connectivity and the Spatial Effects of Wolf Predation on Caribou Survival in Banff and Jasper National Parks. Parks Canada (Banff and Jasper National Parks) Banff National Park. 2014. Available online: https:/ / www.researchgate.net/publication/236651958. (accessed on 26 November 2018). 